\title{
Research on the Problems and Countermeasures of Chinese Automobile Enterprises Transnational Merger and Acquisition
}

\author{
Wei Zheng ${ }^{1} \&$ Zhijun Sheng ${ }^{1}$ \\ ${ }^{1}$ School of Economics and Management, Changchun University of Science \& Technology, Changchun 130022, \\ China \\ Correspondence: Zhijun Sheng, School of Economics and Management, Changchun University of Science \& \\ Technology, Changchun 130022, China. Tel: 86-135-0445-7191. E-mail: shengzhijun412@126.com
}

Received: April 13, 2015

Accepted: April 21, 2015

Online Published: June 15, 2015

doi:10.5430/bmr.v4n2p13

URL: http://dx.doi.org/10.5430/bmr.v4n2p13

This paper is the Achievements of "the Twelfth Five-Year-Plan" social science research project of Education Department of Jilin province. The name of project is "Research on Countermeasures to upgrade the automobile industry cluster in Jilin province from the perspective based on global value chain." (Project number: No. $25^{\text {th }}$ of 2014).

\begin{abstract}
In recently years, affected by the international and domestic economic environment, Chinese automobile enterprises get really perfect time to implement cross-border mergers and acquisitions, so we can see that some Chinese automobile enterprises have already done it. At the same time we should also know there are lots of risks and problems in the process of transnational M\&A, Such as political barriers, legal barriers and cultural conflicts and so on, which often do not make ideal results when they implement the M\&A. At beginning of this paper will talk about the environment of Chinese automobile enterprises transnational M\&A. And then on the basis of analyzing the current situation and problems of Chinese automobile enterprises transnational M\&A, this paper will put forward some suggests which are appropriate for Chinese automobile enterprises.
\end{abstract}

Keywords: Automobile enterprises, Transnational M\&A, Foreign direct investment

\section{Preface}

In the context of economic globalization, information technology globalization, and driven by the impact of quickly updated science and technology, the market competition has become increasingly fierce, so companies have to continue to grow and develop in order to ensure long-term survival. Cross-border mergers and acquisitions are one of important parts of international direct investment and economic development. Cross-border mergers and acquisitions driven by the transfer of industries can alleviate the high dependence on foreign trade and the problem of excess capacity in some industries. (Li \& Yu, 2014) In order to pursue a more long-term development and to achieve higher returns, Chinese enterprises have gradually embarked on the road of cross-border mergers and acquisitions. (Li, 2015) In recent years, M\&A of Chinese companies in the international arena are increasingly active, especially Chinese auto companies. We frequently heard the news of transnational mergers and acquisitions. And the world auto industry was stunned. Chinese auto companies conducted cross-border mergers and acquisitions mostly in order to quickly access advanced technology to quickly enhance their strength, develop their own companies, and eventually enter into the world market. However, we must recognize that the success of cross-border M\&A does not mean the birth of first-class multinational companies. The ability to integrate acquisitions after M\&A is also required to learn and develop. Therefore, it is necessary to study the behavior of Chinese auto companies' M\&A, to analyze the problems encountered in cross-border mergers and acquisitions of the Chinese auto companies, and to give effective responses to the problems of development.

\section{M\&A status of China's automobile enterprises}

In recent years, cross-border mergers and acquisitions of Chinese auto companies are quite common, including the successful stories and the failure ones too. In order to quickly enter the international market, companies choose foreign acquisitions and to make good use of the strengths of foreign auto companies to make up their own weaknesses. On the basis of analyzing China's cases of cross-border mergers in recent years, this paper draws the 
following points of Chinese auto enterprises status.

\subsection{Cross-border mergers and acquisitions of Chinese auto companies have been expanding}

From Beijing Auto's buying of Saab Automobile's intellectual property rights, to BYD's acquisition of large Japanese mold manufacturer, and to the Zhejiang Geely's $\$ 1.8$ billion acquisition of Ford's Volvo 100\% shares and property, the size of these acquisitions continuously upgrade. Geely's acquisition of Volvo is the largest transnational merger among Chinese auto companies. In 2009 Geely decisively seized the opportunity, and made the successful acquisition of Volvo. After the acquisition, Geely mastered the client resources and marketing network of DSI, and expanded their marketing reach. At the same time, through the acquisition, Geely have independent intellectual property rights in the field of automatic transmissions. (Wang, 2015) Volvo has 2500 dealers in more than 100 countries in the world, mostly in Europe and North America, which became the valuable asset for Geely in the world market.

\subsection{Chinese auto companies involved in mergers and acquisitions are diversified}

Initially, as the overall strength of private car companies is not enough, there was little news on their cross-border mergers and acquisitions. However, due to the solid financial strength and solid backing, some state-owned auto companies with the Chinese government's strong support, gradually try mergers and acquisitions of foreign auto companies, e.g. SAIC acquired South Korea's SsangYong Motor Company, NAC acquired British Rover, and Beijing Auto acquired Swedish Saab. However, with the rapid development of China's economy, a number of powerful private car companies have begun to put into mergers and acquisitions activities. For instance, Geely, BYD, Great Wall Motor and other private enterprises have accumulated some capital and experience after years of development. In recent years, many shocking news broke, resulting in increasingly diversified automobile companies involved in mergers and acquisitions in China.

\subsection{Target companies are more concentrated in certain area}

As the automobile industry in developed countries started early, they have very mature technology and management. Automobile giants of the world are concentrated in Europe, the US, Japan and Korea. For example, Geely's acquisition of Volvo of Ford, BYD's acquisition of large mold manufacturing company in Japan and SAIC's acquisition of South Korea's SsangYong Motor, are concentrated in these countries and regions. The global giants of auto companies in these countries and regions are monopolistic on the high-end products market. Chinese auto companies started late, mainly operating in the low-end products. In order to break this limitation, the Chinese auto companies have chosen the way of cross-border M\&A to rapidly access to technology, and the acquired companies and the automobile industry are concentrated in the more developed regions and countries.

\subsection{Most of the acquired enterprises operated difficultly}

Although the development of China's auto companies is very rapid recently, and made a very impressive achievement, the current strength of Chinese automobile enterprises are unable to acquire foreign companies if they are operating in good conditions. Furthermore, if the foreign car business is good, they will not choose to sell out their own business that they painstakingly built up. In 1999 Ford acquired Volvo Car Corporation at a price of $\$ 6.45$ billion. Cars started in 2005 after the merger of Ford consecutive losses, and the amount of the annual loss was up to $\$ 1$ billion. The financial crisis intensified Volvo's losses, reaching to $\$ 1.465$ billion in 2008, despite of a slight improvement in 2009, but still a loss of \$ 653 million. SsangYong's products are mainly diesel-based. In 2008 as international oil price was soaring, the Korean domestic diesel price was higher than gasoline price. And the South Korean government also abolished subsidies on diesel vehicles, which resulted SsangYong Motor went to the brink of bankruptcy and eventually was acquired. Zhejiang Geely Group and Shanghai Automotive companies made M\&A of the target companies when they operated difficultly, which also left a lot of problems.

\section{Problems on Chinese auto companies' M\&A}

\subsection{Lack of proper strategic planning, management lags behind}

Government's support and cross-border M\&A opportunities provide an excellent opportunity for Chinese auto companies' transnational merger. Many car companies began a merger, but they did not establish very clear strategic plan before the merger. They are not clear the M\&A purpose is the market, technology, talents or brand. So there are some failure cases of acquisitions. Moreover, in the Chinese auto companies, although the form of share status is equal with foreign ones, but China is not only the lack of technology and brand, but also a serious lack of funds management experience. (Jia, 2014) Many companies think large-scale means competitive. Some companies think acquisition of a high-end brand and valuable enterprise helps to quickly improve their brand value. In fact, before 
making cross-border mergers and acquisitions, enterprises should recognize that post-merger expansion of the scale is not the ultimate aim, and the ultimate goal is to get its own scarce technology to enhance the competitiveness of Chinese auto companies. In fact, the acquisition is only a method, while the rate of return on investment and efficiency are the ultimate goal. Therefore, the Chinese auto companies must seriously ponder, define their strategic planning, and improve the management level.

\subsection{Difficult to obtain the core technology}

With the rapid development of Chinese economy, Chinese enterprises have gradually shifted to higher value-added products from the production of low value-added products. In the past, the advantage was that China has lower labor costs, but the technology had disadvantage. At present, China's auto industry companies have been able to develop some independent cars, but the technology has not been developed, so it cannot produce higher-level cars. So the major factors of product development gap are: firstly, it cannot be a self-development, production base is poor, and the establishment of independent research and development system face many difficulties; secondly, there is too little investment in research and development of the automotive industry. (Li \& Zhu, 2015) Especially for a Chinese auto company, China's auto market is developing rapidly, and the desire to expand its own brand is growing. In order to fill the gaps in the technical aspects, the Chinese auto companies want to quickly grasp the way through cross-border mergers and acquisitions for high-end technology. However, due to the rapid development of China, foreign companies also sounded the alarm. They fear of the rise of Chinese enterprises. Four major car-producing countries, i.e. the United States, Europe, Japan and South Korea, control the current global auto market. They do not want other companies to get involved, so they are interested in the core technology blockade, and try not to let Chinese auto companies come into contact with core technology.

\subsection{Inaccurate cost estimate on acquisition}

Chinese automobile enterprises' cross-border M\&As are basically supported by the national government and financial institutions Due to the small-scale of Chinese automotive industry with respect to foreign auto companies, like "elephant swallowed by a snake" phenomenon, so the initial costs related to the acquisition of Chinese auto companies have tremendous debt risk. The cost of cross-border mergers and acquisitions are divided into two parts, the initial cost and the later integration costs. The initial acquisition cost paid is just the spot cost, there will be a subsequent post-merger costs and operating costs, which the companies at the time of the acquisition should take into account. And sometimes they even should think of exit costs. Chinese auto companies often only pay attention to the initial cost of carrying out cross-border mergers and acquisitions, and lack of understanding on post-merger integration costs. Late integration costs have huge potential risks, so we must seriously consider the size of the integration costs during mergers and acquisitions. For example, Zhejiang Geely Group acquired Volvo, Ford, and Volvo bided for $\$ 1.8$ billion. It may seem low, but Geely Group need to recognize that this is not the entire US $\$ 1.8$ billion acquisition cost, and they have to invest at least $\$ 2$ billion to revive after the acquisition of Volvo to start up normal operation. The large capital investment for a business is a fatal blow, so if there is no strong capital base, the acquisition will be a failure.

\subsection{Lack of international management talents, existing integration risks}

After auto companies conduct cross-border mergers and acquisitions, merger companies and acquired companies will conduct integration on a variety of resources, which requires excellent management talents. Automobile industry overseas acquisitions will go through the process of the preliminary investigation, negotiation, planning and other aspects of integration, and mergers and acquisitions also have a lot of problems to solve, which are based on various international talents. So the lack of talents has become the major defects on China's automobile enterprises overseas M\&A. Compared to some European and American multinationals, Chinese auto companies are lack of big quantity of international management talents in overseas mergers and acquisitions. If there are no talents to coordinate the entire integration process, post-merger integration behavior will be difficult. If the parties cannot agree on strategic goals, it will lead to the failure of M\&A activity. On March 2010, Geely Group, made a wholly-owned acquisition of the world famous car brand Volvo. (Wang, 2015) In the case of the acquisition of Volvo, Geely's Li Shufu, repeatedly stressed that "Geely is Geely, and Volvo is Volvo", and it doesn't interfere with the development of both. Although it is the case, but for the world high-end brand Volvo, after the acquisition, it is inevitable that the company's original talents will generate a psychological conflict and switch to other businesses. Therefore, post-merger integration of human resources cannot be ignored. 


\section{Suggestions on promoting Chinese auto companies to achieve M\&A}

\subsection{The Government should accelerate the improvement of relevant regulations and standards}

Although many countries accept China's market economy status, but some developed countries with close trade relations with China, like the United States, European Union and Japan still delay to recognize China's market economy status. In order to let the Chinese automobile enterprises, especially many private automobile companies, achieve development goals to be multinational enterprises, the Chinese government must improve laws and standards related to cross-border M\&A for auto companies as soon as possible. If A country has a relatively sound legal system, other countries will be willing to cooperate with developing countries, which will enable Chinese enterprises to conduct cross-border mergers and acquisitions, so that the foreign companies will no longer have concerns about China's economic system, and a foreign government can recognize the Chinese enterprises' M\&A is just to pursue interests, but not other special purposes.

\subsection{Accelerate auto companies' technology to improve the post-merger absorption and innovation capacity and} enhance the international competitiveness

The reasons that Chinese auto companies made cross-border mergers and acquisitions at great risk, are mainly for high-end technology from foreign companies. But with the changes in the global climate and environment, at present many industries are beginning to explore low-carbon energy development path, trying to find new energy sources and new technology to solve global environmental problems facing currently. Especially in the automotive industry, it is a huge industry energy consumption place. When the Chinese auto companies achieved foreign advanced technology, they need to quickly absorb it into their own, and accelerate the pace of innovation on this basis. For this reason the Chinese auto companies want to take advantage of absorbing advanced technology in the automotive roadmap and new energy and environmental protection, actively involve in human, material and financial resources on research and development, and pay attention to cultivate their own core technology. At the same time, the government should give strong support to own brand on the domestic auto companies to cultivate national consciousness of unity, so that China's internal auto companies can unite for the development. Each can play their own advantages and quickly create their own national brand. Only enhancing their competitiveness of ability they can play better in the international market and obtain greater benefits.

\subsection{Clear objectives and strategies to reduce cross-border mergers and acquisitions 'Risk}

Today, the international situation and domestic situation for Chinese auto companies are at a very good time. There is a great temptation, but China's automobile also needs to know the opportunities are often co-exist with the crisis. Before the merger they need to be fully prepared. However, the Chinese auto companies overseas acquisitions are lack of a clear strategic plan, and many companies want to play up in the international market in this favorable environment. But before the merger they did not work out well with the strategic objectives blindness. Therefore, before the merger the auto companies must be clear that you want market, technology, or other assets, and do not follow the trend. After determining the strategic goals, they should pay attention to the future development strategy. Chinese auto companies should look for a strategic direction which two sides can reach a consensus, enable the acquired companies to submit to the acquisition of the auto companies to implement the concept of development of M\&A business, and to minimize risk in the process of strategy and policy enforcement.

\subsection{Develop international vehicles business management talents}

Before cross-border mergers and acquisitions, companies will carry out the preliminary investigation, negotiation, program implementation and so on. After the merger they have a lot of work to do as well. There are a number of risks, and then the transnational management talents are extremely valuable. A high-quality management talents team has played a crucial role in M\&A activities, which often determines the success or failure of mergers and acquisitions. For example, after the acquisition of Daewoo GM car, the United States GM immediately mobilized dozens of people of the elite team to take over the latter part of the Korean market to ensure its smooth progress. While for the Chinese SAIC and SsangYong, due to the lack of international talent reserves, it is difficult to quickly achieve normal operation and management after the acquisition. In the next few years the Chinese government and enterprises should pay attention to focus on training of international talents, so as to lay a solid foundation for future development.

3.5 Strengthen regional cultural integration with the corporate culture, reduce the negative impact caused by cultural differences

Western corporate cultural differences are inevitable, and it is caused by long history factors. Culture itself is not right or wrong. Parent company should integrate its own culture with the local culture and corporate culture after the 
merger as a whole, in order to make a suitable method for the sustainable development of both sides and the common development to explore the management culture of Chinese characteristics, rather than one culture to suppress another one, but to do everything to avoid a conflict between corporate cultures. In order to avoid enormous losses caused by M\&A cultural differences, before the merger companies should fully understand the culture of the host country and the acquired company's culture, so as to analyze the possibility of post-merger cultural integration. But also managers should be trained for cross-cultural in advance in order to establish common values on both sides, creating a consistent corporate culture for both sides.

\section{Conclusion}

In current global market environment, for Chinese automobile enterprises it is a great opportunity to make radical change. Cross-border mergers and acquisitions by Chinese auto companies are feasible to grow rapidly and achieve goals. But they should consider all aspects of mergers and acquisitions, and be slow and steady. The late development of China's auto industry resulted in an imitation of advanced foreign enterprises, so the future path of development must be changed. Specifically, we should improve the domestic market economic system, related laws and regulations; improve technology absorption and innovation capability for auto companies after the merger; clear strategic objectives and implementation strategy of overseas acquisitions, minimize risks of mergers and acquisitions; develop an international management talents team; strengthen regional culture and corporate culture integration, and reduce the negative impact of cultural differences. Although the Chinese auto companies started late, with respect to the backward technology, Chinese auto companies can make use of the advantage to catch up with foreign advanced enterprises, and eventually become a big and strong auto industry country.

\section{References}

Gao shanshan. (2014). Transnational merger of Chinese enterprises in the cultural conflict. Pure, Sep.2014.

Jia Peng, Zheng Xixi. (2015). Status and countermeasures on development of Chinese auto companies. Inner Mongolia Science Technology \& Economy, Dec.2014.

Li Danjie, Zhu Wenjiang. (2015). Chinese automobile overseas acquisitions strategy analysis. Manager' Journal, Jan.2015.

Li Shanmin, Yu Pengyi. (2014). Pattern and strategic choice of Chinese enterprises overseas M\&A. Social Sciences in Nanjing Society \& Science, Dec.2014.

Li Shulin. (2015). Chinese enterprises cross-border M\&A strategy. Money China, Feb.2015.

Wang Hongxing. (2015). Internationalization strategy of Geely Automobile. Manager' Journal, Feb.2015. 